\title{
Orthogonal Experimental Research the Gangue in Gallium Extraction Conditions
}

\author{
Tian Aijie', Tian Aimin ${ }^{2}$, Kong Lingliang ${ }^{3}$, Liu Zhenxue ${ }^{2}$ \\ ${ }^{1}$ Department of Medicine and Health Care, Jinan Technician College, Ji'nan, China \\ ${ }^{2}$ School of Chemical Engineering, Shandong University of Science and Technology, Qingdao, China \\ ${ }^{3}$ Jinan West Railway Station Transportation Co., Ltd., Ji'nan, China
}

\section{Email address:}

Tianaijie_0930@163.com (Tian Aijie)

\section{To cite this article:}

Tian Aijie, Tian Aimin, Kong Lingliang, Liu Zhenxue. Orthogonal Experimental Research the Gangue in Gallium Extraction Conditions. International Journal of Mineral Processing and Extractive Metallurgy. Vol. 5, No. 3, 2020, pp. 37-41. doi: 10.11648/j.ijmpem.20200503.11

Received: August 6, 2020; Accepted: August 21, 2020; Published: August 27, 2020

\begin{abstract}
After mining for many years, the coal gangue piles up, not only occupies a large amount of land, but also causes serious pollution. Therefore, the treatment and utilization of coal gangue has become an important topic for coal mining and environmental protection departments. The inorganic components of coal gangue are mainly $\mathrm{SiO}_{2}$ and $\mathrm{Al}_{2} \mathrm{O}_{3}$, followed by $\mathrm{Fe}_{2} \mathrm{O}_{3}$, generally accounting for $75 \% \sim 80 \%$ of all components. Organic components are mainly composed of Carbon, Hydrogen, Oxygen, Nitrogen and organic Sulfur, accounting for $20 \% \sim 25 \%$ of all components of oal gangue. In addition, the gangue also contains a small amount of Gallium, Alum, Germanium and other rare earth elements. In recent years, the research of extracting Gallium from other raw materials has developed rapidly. In order to make full use of the waste of resources, turning waste into treasure, improve the economic and social benefits, the paper adopted orthogonal experiment to explore the the gangue gallium extraction conditions. The experiments take the high-temperature acid leaching method of orthogonal experimental design experimental conditions. Acid concentration, ignition temperature, ignition time, the acid leaching temperature, leaching time and other factors on the extraction rate of gallium. After a large number of scientific comparison of the experimental conditions, to get the better conditions of the extraction of gallium that acid concentration $6 \mathrm{~mol} / \mathrm{L}$, the ignition temperature of $600^{\circ} \mathrm{C}$, the ignition time $0.5 \mathrm{~h}$, acid leaching temperature of $100^{\circ} \mathrm{C}$, leaching time for $6 \mathrm{~h}$. The extraction rate of $95 \%$, provide a viable experimental conditions for the gangue gallium extraction.
\end{abstract}

Keywords: Gallium, Coal Gangue, Extraction, Orthogonal Experiment

\section{Introduction}

After years of coal mining, the waste coal gangue is piled up like mountains, which not only occupies a lot of land, but also causes serious pollution, thus, solving the problems of coal gangue treatment and utilization has become an important issue for coal mining and environmental protection departments. Coal Gangue has been used for decades in China, In 1989 , the utilization rate of coal gangue was nearly $20 \%$. In recent years, the utilization rate of coal gangue has been increasing because of the importance of environmental work and the progress of science and technology. At present, coal gangue power generation, coal gangue production materials, backfilling, extraction of chemical products and other ways. Coal Gangue with high carbon content can be used as fuel; coal gangue with low carbon content can produce brick, cement and light aggregate; coal gangue with low carbon content can also recover beneficial mineral products such as sulfur, iron and aluminum, coal Gangue can also be used to fill up ditches and subsidence areas, Some coal gangue can also improve the soil, as fertilizer, agricultural carrier. $[1,2]$

We know that the inorganic components of coal gangue are mainly $\mathrm{SiO}_{2}$ and $\mathrm{Al}_{2} \mathrm{O}_{3}$, followed by $\mathrm{Fe}_{2} \mathrm{O}_{3}$, which generally account for $75 \%$ to $80 \%$ of all components of coal gangue. The organic components are mainly composed of carbon, hydrogen, oxygen, nitrogen and organic sulfur, accounting for $20 \%$ to $25 \%$ of all components of coal gangue. In addition, coal gangue also contains a small amount of gallium, alum, germanium and other rare earth elements [3].

Gallium, as a rare and dispersed element, is widely used in 
various fields due to its unique metallic properties. Gallium can be used as a high temperature thermometer and a fire-proof signal device by its low melting point and high boiling point. In the optical instrument industry, a reflector is made by taking advantage of its high reflectivity. In the atomic energy industry, Gallium is used as a heat carrier, it can be used as heat exchange medium in nuclear reactor. Gallium compounds such as GaAs, GaP, GaSb, Ga-As-Sn, Ga-Al-As are widely used in industrial applications such as List of semiconductor materials, optical devices and modern defense. Gallium is mainly used in semiconductor industry. Products based on Gallium compound are used in electronic technology. Gallium-based wafers operate faster than silicon wafers, with wider operating temperatures and emission ranges. With the development of science and technology, Gallium is used more and more widely. In particular, high purity Gallium and Non-ferrous metal Compound semiconductor have become a modern communications, large scale integrated circuits, aerospace, energy, health and other sectors needed to support the new technology materials. Gallium phosphide, gallium arsenic phosphorus based light-emitting Diode, especially high brightness light-emitting Diode and color diodes are developing at a rapid rate, with an estimated annual growth rate of $20 \%-30 \%$. Gallium, a metal used in mobile phones, is also growing rapidly each year, and these fields are rapidly developing into locomotives for the production of gallium-based compounds for traction. Gallium and its compounds, in addition to their applications in the above-mentioned fields, also widely used in broadband fiber communications, personal computers, communications satellite, high-speed signal and image processing, car crash and positioning and car unmanned operating systems and other modern high-tech fields. In addition, gallium is also used in medical and biological fields in the form of gallium nitrate, gallium chloride, such as anti-cancer, the diagnosis and treatment of malignant tumors, advanced hypercalcemia and certain bone diseases. With the development of electronic industry and National Defense Industry, the use of Gallium and its compounds has been gradually expanded. [4-6]

Gallium production has been determined by the market supply and demand of gallium. The great development of gallium production is also in recent years, with the rapid development of electronic industry and related industries, the market of Gallium is in short supply. [7, 8]

Coal Gangue has been used for decades in China. In 1989, the utilization rate of Coal Gangue was nearly $20 \%$. In recent years, due to the importance of environmental work and the progress of science and technology, the utilization rate of Coal Gangue has been increasing. At present, Coal Gangue power generation, Coal Gangue production materials, backfilling, extraction of chemical products and other ways. Coal Gangue with high carbon content can be used as fuel; Coal Gangue with low carbon content can produce brick, cement and light aggregate; Coal Gangue with low carbon content can also recover beneficial mineral products such as Sulfur, Iron and Aluminum, Coal Gangue can also be used to fill up ditches and subsidence areas, and some of them can also be used as fertilizer and agricultural carrier to improve the soil. $[9,10]$

In recent years, the research of extracting gallium from other raw materials develops very fast, such as the extraction from by-products of aluminum smelting industry, from zinc slag of hydrometallurgy, from ore and alum slag, etc., however, generally speaking, gallium leaching mainly has the following two processes: one is high temperature calcination leaching, namely calcination at $500^{\circ} \mathrm{C}$ to $1000^{\circ} \mathrm{C}$, and then leaching with acid $\left(\mathrm{H}_{2} \mathrm{SO}_{4}, \mathrm{HCl}, \mathrm{HNO}_{3}\right.$, etc. $)$ or a mixture of various acids at a certain temperature and pressure to transfer gallium into solution. The reaction is as follows:

$$
\mathrm{Ga}_{2} \mathrm{O}_{3}+6 \mathrm{H}^{+} \rightarrow 2 \mathrm{Ga}^{3+}+3 \mathrm{H}_{2} \mathrm{O}
$$

The other is low temperature acid leaching, namely, adding some additives into acid, and leaching for several hours at 80 to $300^{\circ} \mathrm{C}$ under certain conditions, so that part of gallium is transferred into the solution. However, this method costs a large amount of acid and a long leaching time but its leaching rate is low. High temperature calcination leaching method was adopted in this experiment.

However, when extracting gallium, people mainly determined the extraction process conditions of gallium by exploring, which made the determination of experimental conditions accidental. For this reason, this experiment adopted a scientific method for studying and dealing with the multi-factor experiment - "orthogonal experiment method" to design the experimental scheme, and studied the influence of multiple factors, so that the experiment could select a few experiments with strong representativeness to obtain the optimal or better experimental conditions, and make the determination of experimental conditions more reasonable and reliable.

\section{Drawing of Gallium Standard Curve and Determination of Standard of Gallium Content in Coal Gangue Samples}

\subsection{Apparatus and Reagents}

Analytical balance; crusher, F87-3 pulverizer, standard sample sieve, and splitter; 7200 spectrophotometer and electric heating plate;

Ultrasonic cleaner; Muffle furnace; colorimetric tubes; crucible; water bath and oven.

Sodium hydroxide (solid); ethanol; hydrochloric acid; titanium trichloride solution: analytical reagent, 15\%; Rhodamine B solution, 0.5\%;

Benzene-ether mixed solvent (3:1); gallium stock solution: $200.00 \mathrm{ug} / \mathrm{ml}$; and gallium working solution: $2.00 \mu \mathrm{g} / \mathrm{ml}$.

\subsection{Sampling and Preparation of Coal Gangue Samples}

The coarse coal gangue samples used in this experiment were from the gangue dump of Jining No. 2 Coal Mine. The coal gangue samples were relatively wet. Before sample 
preparation, they were naturally dried without damage, and then crushed, pulverized, sieved $(0.2 \mathrm{~mm})$ - uniformly mixed, so that all the samples passed through the $0.2 \mathrm{~mm}$ sample sieves, and then were dried continuously and sealed for standby.

\subsection{Drawing of Gallium Standard Curve (GB) [11]}

Respectively added the working solutions containing 0.00 , $0.00,1.00,2.00,3.00,4.00$ and $5.00 \mu \mathrm{g}$ of gallium into $25 \mathrm{ml}$ covered colorimetric tubes, and diluted them to $10 \mathrm{ml}$ with 6 mol / L hydrochloric acid. Added $0.5 \mathrm{ml}$ of titanium trichloride solution and shook well. After $5 \mathrm{~min}$, added $2 \mathrm{ml}$ rhodamine B solution and shook well. Then added $6.0 \mathrm{ml}$ of benzene-ether mixed solvent and extracted for $2 \mathrm{~min}$. After standing and layering, cleaned the orifices and covers of the colorimetric tubes with filter paper, and carefully absorbed the organic extraction solution with dry pipettes. Put them into $1 \mathrm{~cm}$-thick covered colorimetric tanks, and measured their absorbance with a wavelength of $560 \mathrm{~nm}$ on a spectrophotometer with the benzene-ether solvent as the reference. Solved the regression equation of gallium standard curve according to the linear regression method.

Table 1. Results of standard curve determination

\begin{tabular}{llllllll}
\hline Ga $(\boldsymbol{\mu g})$ & Blank & Blank & $\mathbf{1}$ & $\mathbf{2}$ & $\mathbf{3}$ & $\mathbf{4}$ & $\mathbf{5}$ \\
\hline Absorbance (A) & 0.017 & 0.012 & 0.166 & 0.310 & 0.460 & 0.604 & 0.757 \\
Corrected (A) & 0.014 & & 0.152 & 0.296 & 0.446 & 0.590 & 0.743 \\
\hline
\end{tabular}

Linear regression method was used to calculate the regression equation and correlation coefficient of the measured data as follows:

$$
G a^{3+}(\mu g)=6.774 A-0.014
$$

$$
\rho=0.99995 \rho>0.9990
$$

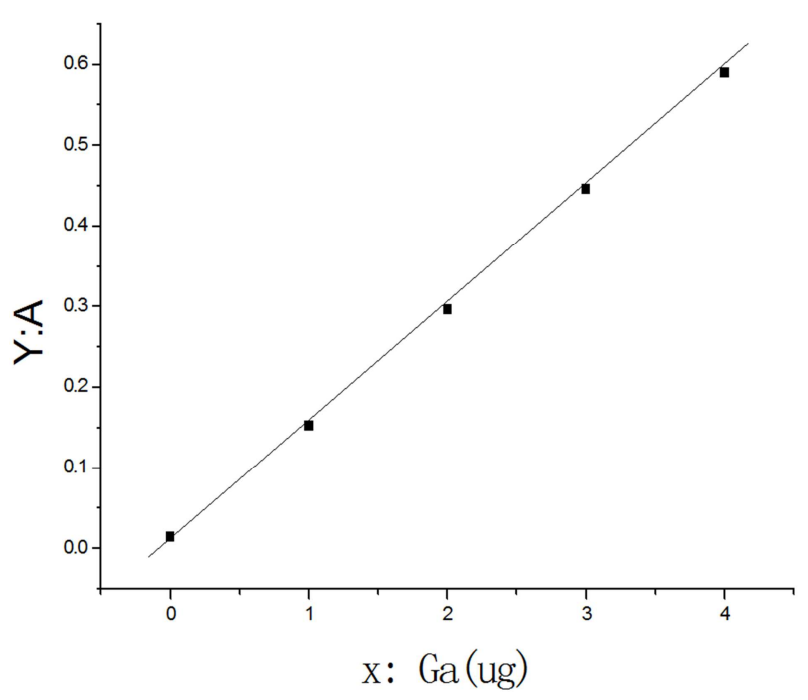

Figure 1. The standard curve of $G a$.

\subsection{Determination of Gallium Content in Coal Gangue [11] (GB)}

Accurately weighed two $1 \mathrm{~g}$ (accurate to $0.2 \mathrm{mg}$ ) coal gangue samples and put them a in clean silver crucible with a cover, added a small amount of ethanol to wet the ash, added $4 \mathrm{~g}$ of sodium hydroxide solid, and then put the crucible into the Muffle furnace, gradually raised the temperature to $700{ }^{\circ} \mathrm{C}$ and melt for 15 min under natural ventilation. After cooling, transferred all samples into a $250 \mathrm{ml}$ beaker with a cover, and added $1 \mathrm{ml}$ ethanol and $100 \mathrm{ml}$ boiling water into the crucible. After leaching, washed out the crucible and cover with hot water. Slowly added $10 \mathrm{ml}$ of $6 \mathrm{M}$ hydrochloric acid from the beaker. After the molten materials were completely dissolved, uncovered the beaker cover and rinsed with distilled water. Then heated the beaker on a low-temperature electric heating plate to evaporate the solution. After the salt precipitated and dried up, used a pan headed glass rod to stir and grind the salt lumps until they were completely dried up. When slightly cooled it, added $40 \mathrm{ml}$ of $6 \mathrm{M}$ hydrochloric acid with the pipette accurately and shook well for colorimetric determination.

Respectively took two copies of $2 \mathrm{~mL}$ and $10 \mathrm{~mL}$ (or $2 \mathrm{~mL}$, $8 \mathrm{~mL}$ ) of each sample, and placed them in 4 clean colorimetric tubes and diluted them to $10 \mathrm{~mL}$ with $6 \mathrm{~mol} / \mathrm{L}$ hydrochloric acid: added $0.5 \mathrm{~mL}$ titanium trichloride solution and shook well; added $2 \mathrm{ml}$ of rhodamine B solution after placing for $5 \mathrm{~min}$, and shook well; then added $6.0 \mathrm{~mL}$ of benzene-ether mixed solvent for extraction of two minutes; after standing and layering, cleaned the orifices and covers of colorimetric tubes with filter paper, and carefully sucked out the organic extraction solution with dry pipettes, and put them into $1 \mathrm{~cm}$-thick colorimetric tanks with covers with the benzene-ether mixed solvenet as the reference, and measured the absorbance on the spectrophotometer.

Table 2. Results of determination of gallium content in coal gangue of Jining

\begin{tabular}{|c|c|c|c|c|c|c|c|}
\hline $\begin{array}{l}\text { Extraction } \\
\text { volume }(\mathrm{ml})\end{array}$ & Blank & Blank & 2.00 & 10.00 & 2.00 & 10.00 & Mean \\
\hline Absorbance (A) & 0.009 & 0.006 & 0.155 & 0.707 & 0.158 & 0.723 & \\
\hline $\mathrm{Ga}(\mu \mathrm{g} / \mathrm{g})$ & & & 19.70 & 19.10 & 20.13 & 19.53 & 19.53 \\
\hline
\end{tabular}
No. 2 Coal Mine.

Therefore, the content of gallium in coal gangue used in this experiment was about $19.53 \mathrm{ug} / \mathrm{g}$, which provided comparable data for the extraction rate of this experimental method.

\section{Determination of Gallium Content in Coal Gangue Samples}

Through the orthogonal experiment, this experiment design discussed the influences of ignition temperature, ignition time, acid concentration, acid leaching time and acid leaching temperature on the extraction rate of gallium, and analyzed the experimental data according to the range method, so as to obtain the optimal experimental conditions.

\subsection{Preliminary Determination of Experimental Conditions}

The four-factor and four-level test was selected according to the reference data:

Factor A: ignition temperature: $500^{\circ} \mathrm{C}, 600^{\circ} \mathrm{C}, 700^{\circ} \mathrm{C}, 800^{\circ} \mathrm{C}$; Factor B: ignition time: $0.5 \mathrm{~h}, 1.0 \mathrm{~h}, 1.5 \mathrm{~h}, 2.0 \mathrm{~h}$; 
Factor C: acid leaching temperature: $100^{\circ} \mathrm{C}, 80^{\circ} \mathrm{C}, 60^{\circ} \mathrm{C}$, $40^{\circ} \mathrm{C}$;

Factor D: acid leaching time: $8 \mathrm{~h}, 6 \mathrm{~h}, 4 \mathrm{~h}, 2 \mathrm{~h}$

The solid-liquid ratio (mass of coal gangue sample: volume of hydrochloric acid) was tentatively 1g: $40 \mathrm{ml}$. The concentration of hydrochloric acid was $6 \mathrm{~mol} / \mathrm{L}$.

The orthogonal table $L_{16}\left(4^{5}\right)$ was selected according to the above conditions, as shown in Table 3. The experimental design and results are listed in the table.

Table 3. Orthogonal table $L_{16}\left(4^{5}\right)$.

\begin{tabular}{lllllll}
\hline \multirow{2}{*}{$\begin{array}{l}\text { Test } \\
\text { No. }\end{array}$} & \multicolumn{2}{l}{ Column No. } & & & $\begin{array}{l}\text { Ga } \\
\text { (ug/g) }\end{array}$ \\
\cline { 2 - 6 } & $\mathbf{1}(\mathbf{A})$ & $\mathbf{2}(\mathbf{B})$ & $\mathbf{3}(\mathbf{C})$ & $\mathbf{4}(\mathbf{D})$ & $\mathbf{5}$ & 20.55 \\
1 & 1 & 1 & 1 & 1 & 1 & 13.31 \\
2 & 1 & 2 & 2 & 2 & 2 & 11.28 \\
3 & 1 & 3 & 3 & 3 & 3 & 6.53 \\
4 & 1 & 4 & 4 & 4 & 4 & 13.24 \\
5 & 2 & 1 & 2 & 3 & 4 & \\
\hline
\end{tabular}

\begin{tabular}{|c|c|c|c|c|c|c|}
\hline \multirow{2}{*}{$\begin{array}{l}\text { Test } \\
\text { No. }\end{array}$} & \multicolumn{5}{|c|}{ Column No. } & \multirow{2}{*}{$\begin{array}{l}\text { Ga } \\
(\mathbf{u g} / \mathrm{g})\end{array}$} \\
\hline & $1(\mathrm{~A})$ & $2(\mathrm{~B})$ & $3(\mathrm{C})$ & 4 (D) & 5 & \\
\hline 6 & 2 & 2 & 1 & 4 & 3 & 17.17 \\
\hline 7 & 2 & 3 & 4 & 1 & 2 & 7.28 \\
\hline 8 & 2 & 4 & 3 & 2 & 1 & 11.55 \\
\hline 9 & 3 & 1 & 3 & 4 & 2 & 11.34 \\
\hline 10 & 3 & 2 & 4 & 3 & 1 & 11.07 \\
\hline 11 & 3 & 3 & 1 & 2 & 4 & 15.47 \\
\hline 12 & 3 & 4 & 2 & 1 & 3 & 13.71 \\
\hline 13 & 4 & 1 & 4 & 2 & 3 & 4.7 \\
\hline 14 & 4 & 2 & 3 & 1 & 4 & 12.43 \\
\hline 15 & 4 & 3 & 2 & 4 & 1 & 6.02 \\
\hline 16 & 4 & 4 & 1 & 3 & 2 & 18.32 \\
\hline
\end{tabular}

Note: [1] the first four columns in Table 1 are the four factors discussed, and the order is: ignition temperature, ignition time, acid leaching temperature and acid leaching time; the fifth item is error term. [2] Each column number corresponds to the level item of each factor, and the order is shown in Table 3.

Analysis of results in Table 3.

Table 4. Analysis of range method.

\begin{tabular}{llllll}
\hline \multirow{2}{*}{ Level } & Factor & & & & \\
\cline { 2 - 6 } & A Ignition temperature & B Ignition time & C Acid leaching temperature & D Acid leaching time & Error \\
\hline$I_{j}$ & 51.67 & 49.83 & 71.51 & 54.51 & 49.19 \\
$I I_{j}$ & 49.78 & 53.98 & 56.88 & 45.03 & 50.97 \\
$I I I_{j}$ & 54.59 & 50.59 & 46.6 & 53.91 & 46.86 \\
$I V_{j}$ & 51.47 & 50.11 & 30.12 & 51.06 & 47.67 \\
$R_{j}$ & 4.81 & 4.15 & 41.39 & 9.48 & 4.11 \\
\hline
\end{tabular}

It can be seen from Table 4 that the range of factor $\mathrm{C}$ is the largest $(\mathrm{RC}=41.39)$, while the influences of $\mathrm{D}, \mathrm{A}$ and $\mathrm{B}$ are not obvious. Also from Table 4, the order of influences of all levels of factor $\mathrm{C}$ on the extraction rate (from high to low) is IC $>$ II C > III C > IV C, that is, the first level of factor C (acid leaching temperature is $100^{\circ} \mathrm{C}$ ) is better. The acid leaching temperature can be selected as $100^{\circ} \mathrm{C}$, and the acid leaching time, ignition temperature and ignition time are not obvious, so the test can be continued.

At this time, the extraction rate is $\frac{(20.55+17.17+15.47+18.32) \div 4}{19.53}=91.54 \%$

\subsection{Optimization of Experimental Conditions}

According to the above test results and the influence of acidity, the optimization conditions of the test were further determined,

Factor A: ignition temperature: $400^{\circ} \mathrm{C}, 450^{\circ} \mathrm{C}, 500^{\circ} \mathrm{C}$

Factor B: ignition time: 30, 60, $90 \mathrm{~min}$

Factor C: acidity: 6M, 4M, 2M

Additional: $500^{\circ} \mathrm{C}, 30 \mathrm{~min}, 6 \mathrm{~mol} / \mathrm{L}$

Acid leaching temperature: $100^{\circ} \mathrm{C}$, tentative acid leaching time: 4 hours (other conditions were not changed)

Selected Table 5 of orthogonal experiment, and the experimental design and results were listed in the table.
Table 5. Orthogonal experiment.

\begin{tabular}{llllll}
\hline \multirow{2}{*}{$\begin{array}{l}\text { Experiment } \\
\text { No. }\end{array}$} & \multicolumn{5}{l}{ Column No. } \\
\cline { 2 - 5 } & $\mathbf{1}(\mathbf{A})$ & $\mathbf{2}(\mathbf{B})$ & $\mathbf{3}(\mathbf{C})$ & $\mathbf{4}$ & Result (ug/g) \\
\hline 1 & 1 & 1 & 1 & 1 & 16.23 \\
2 & 1 & 2 & 2 & 2 & 9.46 \\
3 & 1 & 3 & 3 & 3 & 10.83 \\
4 & 2 & 1 & 2 & 3 & 16.11 \\
5 & 2 & 2 & 3 & 1 & 15.16 \\
6 & 2 & 3 & 1 & 2 & 17.46 \\
7 & 3 & 1 & 3 & 2 & 16.09 \\
8 & 3 & 2 & 1 & 3 & 18.12 \\
9 & 3 & 3 & 2 & 1 & 17.74 \\
Additional & & & & & 18.55 \\
\hline
\end{tabular}

Results in Table 5 were analyzed.

Table 6. Range analysis.

\begin{tabular}{|c|c|c|c|c|}
\hline \multirow{2}{*}{ Level } & \multicolumn{4}{|l|}{ Factor } \\
\hline & A ignition temperature & B ignition time & C Acidity & Error \\
\hline$I_{j}$ & 36.52 & 48.43 & 51.81 & 49.13 \\
\hline$I I_{j}$ & 48.73 & 42.74 & 43.31 & 43.01 \\
\hline$I I I_{j}$ & 51.95 & 46.03 & 42.08 & 45.06 \\
\hline$R_{j}$ & 15.43 & 5.69 & 9.73 & 6.12 \\
\hline
\end{tabular}

It can be seen from Table 5 that the range of factor $\mathrm{A}$ (ignition temperature) is the largest $(\mathrm{RA}=15.43)$, followed by $\mathrm{C}$ (acidity), while the influence of $\mathrm{B}$ (ignition time) is not obvious, so the order of influences of factors on extraction rate 
(from high to low) can be determined as follows: $\mathrm{A} \rightarrow \mathrm{C} \rightarrow \mathrm{B}$

It can also be seen from Table 5 that IIIA $>$ IIA $>$ IA, that is, the third level of $\mathrm{A}\left(500^{\circ} \mathrm{C}\right)$ is better; and I C $>$ II C $>$ III C, that is, the first level of $\mathrm{C}(6 \mathrm{M})$ is better. The influence of ignition time is not obvious, and can be set as a short time of $30 \mathrm{~min}$.

Therefore, the higher the ignition temperature is, the better the result will be. It can further discuss at $500^{\circ} \mathrm{C}, 550{ }^{\circ} \mathrm{C}$ and $600^{\circ} \mathrm{C}$. The higher the acidity is, the better the result will be. Considering the consumption amount of acid, $6 \mathrm{M}$ hydrochloric acid can be used. The influence of ignition time from $0.5 \mathrm{~h}$ to $2 \mathrm{~h}$ is not obvious, so it can be set as $0.5 \mathrm{~h}$. The acid leaching time can be further discussed.

At this time, the extraction rate is $\frac{18.55}{19.53}=94.98 \%$

\subsection{Further Optimization of Experimental Conditions}

The optimization conditions of test were further discussed according to the above test results.

Factor A: ignition temperature: $500^{\circ} \mathrm{C}, 550^{\circ} \mathrm{C}, 600^{\circ} \mathrm{C}$

Factor B: acid leaching time: $4 \mathrm{~h}, 6 \mathrm{~h}$ (other conditions were not changed)

Tested according to the set conditions, and the results are listed in the table.

Table 7. Test design and results.

\begin{tabular}{llll}
\hline \multirow{2}{*}{ Experiment No. } & \multicolumn{2}{l}{ Factor } & \multirow{2}{*}{ Result $(\boldsymbol{\mu g} / \mathbf{g})$} \\
\cline { 2 - 3 } & A & B & 16.35 \\
\hline 1 & 1 & 1 & 18.26 \\
2 & 1 & 2 & 17.65 \\
3 & 2 & 1 & 18.87 \\
4 & 2 & 2 & 17.92 \\
5 & 3 & 1 & 18.87 \\
6 & 3 & 2 & \\
\hline
\end{tabular}

Results in Table 7 were analyzed.

Table 8. Range analysis.

\begin{tabular}{lll}
\hline \multirow{2}{*}{ Level } & Factor & \\
\cline { 2 - 3 } & Ignition temperature & Acid leaching time \\
\hline 1 & 34.61 & 51.92 \\
2 & 36.52 & 56.00 \\
3 & 36.79 & \\
\hline
\end{tabular}

Obviously, the ignition temperature has little influence, but the high temperature is slightly better, so $600^{\circ} \mathrm{C}$ can be selected. The acid leaching time also has little influence, but the extended time is more powerful, so $6 \mathrm{~h}$ can be selected.

At this time, the extraction rate has reached $\frac{18.87}{19.53}=96.62 \%$.

\section{Conclusion}

The test used the high temperature calcination leaching method to study the extraction of gallium in coal gangue, designed the experimental conditions by orthogonal experiment method, and discussed the influences of acid concentration, ignition temperature, ignition time, acid leaching temperature and acid leaching time on the extraction rate of gallium. After comparing a lot of scientific experimental conditions, the optimum process conditions of gallium extraction are obtained, namely, the acid concentration of $6 \mathrm{~mol} / \mathrm{L}$, the ignition temperature of $600^{\circ} \mathrm{C}$, the ignition time of $0.5 \mathrm{~h}$, the acid leaching temperature of $100^{\circ} \mathrm{C}$ and the acid leaching time of $6 \mathrm{~h}$, which makes the extraction rate reach $95 \%$ or above.

The experiment adopted the orthogonal experimental design. Because many factors were studied at the same time, the experimental efficiency was improved, and the determination of process conditions was more reliable and reasonable. This extraction method and process conditions can reduce the production cost of gallium, simplify the operation, make full use of waste resources, provide a new idea for further obtaining low-cost metal gallium as well as provide feasible experimental conditions for the extraction of gallium from coal gangue.

\section{References}

[1] Cui Shujun, Yan Yunming. Geochemical Characteristics and Agricultural Utilization Prospect of Coal Gangue. Zhongzhou Coal, 1999 (1): 30

[2] Liu Guangyi, Dai Tayin. Comprehensive Utilization of Gallium-rich Coal Gangue. China Resources Comprehensive Utilization, 2000, (12): 16-19.

[3] Collection of coal experimental methods (National Standard of the People's Republic of China 1992).

[4] Liu Guihua, Li Xiaobin, Zhang Chuanfu, etc. Solvent extraction of gallium. Rare metals and cemented carbides, 1998 (132): 48-51.

[5] Li Yuping, Li Lifen, Wang Xianke. Determination of gallium by liquid membrane separation. Hunan Metallurgy, 2001, (1): 36-39.

[6] Zhang XiuYiong. Study on the extraction of gallium by a new extractant CA-120258-7076(2002)01-0065 Foshan 04.

[7] Taihong Shi, Songping Wang, Yinhua Wan, et Al. Rcovery of Gallium form Zinc Hydrometallurgy System by Emulsion Liquid membrane. Rare METALS, 1998, 17 (4): 260-265.

[8] FangZheng. ACID leaching of gallium from coal dust and extraction of a foam sponge. Journal of Central South University, 1994, 25 (6): 762-766.

[9] He GuiZhen, Hu Xiaolian, Li YunYong. Leaching test conditions of gallium from fly Ash. Comprehensive Utilization of fly Ash, 2002 (6): 11-13.

[10] Lü LiXia. Recovery of gallium in alumina plant. Light Metals, 2002, (5): 15-17.

[11] Li Haizhen, Jiang you. Comprehensive application of Coal Gangue 1008-8725(1999)05-0025-02. 